\title{
Applications of Artificial Intelligence for Static Poisson's Ratio Prediction While Drilling
}

\author{
Ashraf Ahmed, Salaheldin Elkatatny $(D$, and Ahmed Alsaihati \\ College of Petroleum Engineering and Geosciences, King Fahd University of Petroleum and Minerals, \\ Dhahran 31261, Saudi Arabia \\ Correspondence should be addressed to Salaheldin Elkatatny; elkatatny@kfupm.edu.sa
}

Received 4 March 2021; Revised 10 April 2021; Accepted 27 April 2021; Published 4 May 2021

Academic Editor: Rodolfo E. Haber

Copyright $(92021$ Ashraf Ahmed et al. This is an open access article distributed under the Creative Commons Attribution License, which permits unrestricted use, distribution, and reproduction in any medium, provided the original work is properly cited.

The prediction of continued profile for static Poisson's ratio is quite expensive and requires huge experimental works, and the discontinuity in the measurement and the limited applicability and accuracy of the present empirical correlations necessitated the utilization of artificial intelligence with its prosperous application in oil and gas industry. This work aims to construct different artificial intelligence models for predicting static Poisson's ratio of complex lithology at real time during drilling. The functional networks (FN) and random forest (RF) approaches were utilized using the mechanical drilling parameters as inputs. This study uses a vertical well with 1775 records from complex lithology containing shale, sand, and carbonate for model building. Besides, a different dataset from another well was used to check the models' validity. The results demonstrated that both FN- and RF-based models predicted static Poisson's ratio with significant matching accuracy. The FN technique results' correlation coefficient $(R)$ value of 0.89 and average absolute percentage error (AAPE) values of $10.23 \%$ and $10.28 \%$ in training and testing processes. While the RF technique is outperformed, as illustrated by the highest $R$ values of 0.99 and 0.94 and the lowest AAPE values of $1.89 \%$ and $5.19 \%$ for training and testing processes, the robustness and reliability of the developed models were confirmed in the validation process with $R$ values of 0.94 and 0.86 and AAPE values of $11.23 \%$ and $5.12 \%$ for FN- and RF-based models, respectively. The constructed models developed a basis for inexpensive static Poisson's ratio prediction in real time with significant accuracy.

\section{Introduction}

Poisson's ratio $(\nu)$ is an elastic geomechanical characteristic defined as the ratio between transversal and axial strains. It measures the rock's ability to recuperate from a deformation resulted by external strains and defines the relationship between these strains and the caused deformation [1]. Knowing Poisson's ratio with the other rock elastic properties helps design hydraulic fracturing and interpret the in situ stresses, drilling performance, and wellbore stability [2-5], which help in optimizing the drilling operations, well planning, and development of completion and production strategies.

In practical, Poisson's ratio varies from 0.0 to 0.5 and has two types: static $\left(v_{s t}\right)$ and dynamic $\left(v_{d y n}\right)$. The static is determined experimentally from compressional tests, while the dynamic derived from the shear and compressional wave velocities from well logs. The high expenses and discontinuity in the $v_{s t}$ measurement necessitated its prediction using empirical relationships. Different correlations were developed to predict the $v_{s t}$ using $v_{d y n}$ or compressional and/ or shear wave velocities $\left(V_{p}\right.$ and $\left.V_{s}\right)$ with different empirical coefficients, as summarized in Table 1.

The abovementioned empirical correlations have reliability limitations and depend on the availability of $V_{P}$ and $V_{S}$. Since the artificial intelligence (AI) can be applied for inexpensively analysing and interpreting tremendous data and trends to obtain outputs in least time [9], it can be utilized to predict a continued profile of Poisson's ratio.

The AI techniques became a hotspot in petroleum industry since the early nineties and applied in different aspects $[10,11]$. The AI was applied in exploration to predict the feature recognition [12], travel time calculation [13, 14], and clarity and resolution of seismic data enhancement [15]. 
Several AI models were applied in drilling aspects such as operations monitoring, data correction, and prediction of drilling parameters and mud properties [16-25]. Also, in reservoir and production engineering, the AI was applied in prediction of reservoir characteristics, inflow performance, production rate, and others [26-38].

Different AI models were developed to estimate the $v_{s t}$, using the artificial neural network (ANN), support vector machine (SVM), alternating conditional expectation (ACE), fuzzy logic (FL), functional networks (FN), and adaptive neuro-fuzzy inference system (ANFIS), as listed in Table 2.

From a practical point of view, the drilling parameters, such as weight on bit (WOB), standpipe pressure (SPP), torque $(T)$, rotation speed (RPM), pumping rate $(Q)$, and rate of penetration (ROP) are linked to the formation features and measured at real time [48-50], Consequently, these mechanical parameters can be correlated to $v_{s t}$ as a geomechanical rock property.

This work aims to construct different models to predict real-time static Poisson's ratio $\left(v_{s t}\right)$ of complex lithology during drilling. The functional networks (FN) and random forest (RF) approaches were applied, and the drilling parameters including WOB, $T$, SPP, RPM, ROP, and $Q$ were used as inputs. In the following sections, the datasets are described, analysed, and preprocessed. Then, the outputs of the developed models are presented and validated using different datasets.

\section{Methodology}

2.1. Data Description. Different datasets were obtained from an intermediate section with a 12.25 " hole diameter of two vertical wells having penetrating formations with complex lithology of sand, shale, and carbonate. These datasets contained the real-time drilling parameters, including the WOB, T, SPP, RPM, ROP, and Q, which were measured at the surface while drilling and the corresponding $v_{s t}$ from core experiments and conventional logs. The drilling parameters were used as inputs in the models, and the output is $v_{s t}$. The dataset from the first well containing more than 1775 records is used to construct the models, while the other well's dataset with 762 records is only used to validate the developed models.

2.2. Data Analysis and Processing. The obtained data was studied and processed before using the AI approaches to examine the data quality, reliability, and representation. Statistics of the drilling parameters and $v_{s t}$ are outlined in Table 3. An extensive range of mechanical drilling parameters and $v_{s t}$ with good data distribution coverage were indicated from the statistics.

Moreover, the linear relationship strength between the drilling parameters and $v_{s t}$ was addressed by defining the correlation coefficient $(R)$ to measure the relative significance of the drilling parameters for $v_{s t}$, as illustrated in Figure 1. Although the correlation coefficient between $v_{s t}$ and SPP indicated almost no linear relation, the SPP varied significantly with changes of $v_{s t}$. The same behaviour depicted the other parameters; nonlinear relation may exist. Accordingly, all drilling parameters will be considered as inputs.

Data filtration and cleaning were conducted to remove impractical values, noises, and outliers, which improve the data quality and confidence. The tools' limitations, feasible ranges of drilling parameters, and statistical analyses were accounted in these preprocesses.

2.3. Models' Development. The cleaned data was divided into $70 / 30 \%$ (1243/532 datapoints) to train/test the models on a random basis. The FN- and RF-supervised learning AI techniques were utilized using Python software with the Scikit-Learn ${ }^{\circledR}$ framework. Sensitivity analyses and tuning process were performed to determine the optimum parameters for each model. Then, the constructed models were evaluated using the data records from the second well.

The FN and RF techniques were nominated for using since they were recently applied in oil and gas industry $[34,44,51]$ with encouraging outputs and simplicity.

Multiargument functional models are used in the FN approach to learn and process from the data. This technique relies on both data knowledge and domain. The model's accuracy depends on selecting the best method and type in the FN algorithm. It included five methods (i.e., forward selection (FS), exhaustive search (ES), backward-forward $(\mathrm{BF})$, forward-backward (FB), and backward elimination $(\mathrm{BE}))$ that were tested with the two types of linear and nonlinear to build the optimal model.

On the contrary, the RF technique depends on bagging and bootstrapping procedures. Numerous decision trees are combined and decorrelated, and these processes are performed by randomly choosing parameters at each candidate split. The optimal model parameters of decision trees' number (n_estimators), depth of each tree (max_depth), minimum number of samples desired to divide an internal node (min_samples_split), minimum sample leaf size required to be at the end node (min_sample_leaf), and maximum number of features (max_features) were defined using the tuning process.

The optimality of each model was examined for the highest $R$ and lowest AAPE values. The equations for $R$ and AAPE calculations are presented in Appendix A.

The flowchart for the methodology of developing the FN/RF is shown in Figure 2.

\section{Results and Discussion}

3.1. FN Model. The backward-forward (BF) method with the nonlinear type resulted the highest matching accuracy specified by the $R$ value of 0.89 and AAPE values of $10.23 \%$ and $10.28 \%$ in training and testing processes. Figures 3 and 4 describe the matching in the cross plots and graphical representations of predicted and actual $v_{s t}$, respectively.

3.2. RF Model. The parameters' tuning process indicated that the superior RF model was acquired using the optimized parameters mentioned in Table 4. 
Table 1: Empirical correlations for static Poisson's ratio prediction.

\begin{tabular}{|c|c|c|}
\hline Authors & Equations & Remarks \\
\hline \multirow[t]{2}{*}{$\begin{array}{l}\text { Christaras et al. } \\
{[6]}\end{array}$} & \multirow[t]{2}{*}{$v_{s t}=0.71 v_{d y n}+0.063$} & $\begin{array}{c}\text { A correlation between } v_{s t} \text { and } v_{d y n} \text { was proposed using } 8 \text { samples from several rock kinds } \\
\text { (i.e., gypsum, phonolite, basalts, granite, limestone, and andesite) } \\
\text { The correlation coefficient }(R) \text { of this model in the specified rock types is } 0.737\end{array}$ \\
\hline & & $\begin{array}{c}\text { The same approach was followed to obtain a linear correlation between } v_{s t} \text { and } \nu_{d y n} \text { using } 18 \\
\text { samples from sandstone and siltstone rocks } \\
\text { The empirical coefficients vary with the porosities }\end{array}$ \\
\hline Feng et al. [7] & $v_{s t}=a v_{d y n}-b$ & $\begin{array}{c}\text { The coefficient of determination }\left(R^{2}\right) \text { is } 0.92 \text { and } 0.7 \text { for modelling and testing samples, } \\
\text { respectively }\end{array}$ \\
\hline \multirow{2}{*}{ Wang et al. [8] } & \multirow{2}{*}{$v_{s t}=a V_{p}+b v_{s t}=c V_{s}+d$} & $\begin{array}{c}V_{P} \text { and } V_{S} \text { were used to develop two correlations for } v_{s t} \text { prediction at different rocks } \\
\text { The empirical parameters change with different rock types }\end{array}$ \\
\hline & & The $R$ values range from $0.467-0.834$ and $0.668-0.914$ for the two models, respectively \\
\hline
\end{tabular}

TABle 2: The developed AI models for static Poisson's ratio prediction.

\begin{tabular}{|c|c|c|c|c|}
\hline Authors & Inputs & AI techniques & $\begin{array}{c}\text { No. of } \\
\text { datapoints }\end{array}$ & Remarks \\
\hline $\begin{array}{l}\text { Abdulraheem } \\
\text { et al. [39] }\end{array}$ & Travel time and bulk density & $\begin{array}{c}\text { ANN, FL, and } \\
\text { FN }\end{array}$ & 77 & $R=0.10-0.91$ \\
\hline Al-anazi et al. [40] & $\begin{array}{l}\text { Bulk density, depth, pore pressure, overburden stresses, } \\
\text { minimum horizontal stresses, porosity, and compressional } \\
\text { and shear travel times }\end{array}$ & ACE & 602 & $R=0.997$ \\
\hline Tariq et al. [41] & $V_{p}$ and $V_{s}$ & ANN & 550 & $\begin{array}{c}\text { Carbonate } \\
\text { formations } \\
R=0.985\end{array}$ \\
\hline $\begin{array}{l}\text { Elkatatny et al. } \\
\text { [42] }\end{array}$ & Bulk density and compressional and shear times & ANN & 610 & $\begin{array}{l}\text { Carbonate } \\
\text { formations } \\
R=0.985\end{array}$ \\
\hline Elkatatny [43] & Sonic travel times and bulk density & $\begin{array}{c}\text { ANN, ANFIS, } \\
\text { and SVM }\end{array}$ & 610 & $\begin{array}{l}\text { Carbonate } \\
\text { formations } \\
R=0.933-0.985\end{array}$ \\
\hline Tariq et al. [44] & Bulk density, gamma ray, porosity, and $V_{p}$ and $V_{s}$ & $\mathrm{FN}$ & 580 & $\begin{array}{l}\text { Carbonate } \\
\text { formations } \\
R=0.985\end{array}$ \\
\hline $\begin{array}{l}\text { Abdulraheem } \\
\text { [45] }\end{array}$ & $V_{p}$ and $V_{s}$ & $\mathrm{ANN}$ and $\mathrm{FL}$ & 75 & $\begin{array}{c}\text { Carbonate } \\
\text { formations } \\
\text { AAPE }^{*}=5.16-8.20 \%\end{array}$ \\
\hline Gowida et al. [46] & Bulk density and sonic log & $\begin{array}{l}\text { ANN coupled } \\
\text { with } \mathrm{DE}^{* *}\end{array}$ & 692 & $\begin{array}{c}\text { Sandstone } \\
R=0.964\end{array}$ \\
\hline Ahmed et al. [47] & Drilling parameters & $\begin{array}{l}\text { ANN, ANFIS, } \\
\text { and SVM }\end{array}$ & 1775 & $R=0.90-0.96$ \\
\hline
\end{tabular}

${ }^{*} \mathrm{AAPE}=$ average absolute percentage error. ${ }^{* *} \mathrm{DE}=$ differential evolution algorithm.

Table 3: Statistics of the obtained dataset.

\begin{tabular}{|c|c|c|c|c|c|c|c|}
\hline Parameter & WOB $\left(\mathrm{klb}_{\mathrm{m}}\right)$ & $\mathrm{T}\left(\mathrm{klb}_{\mathrm{f}} \mathrm{ft}\right)$ & SPP (psi) & RPM & ROP (ft/hr) & $\mathrm{Q}(\mathrm{gal} / \mathrm{min})$ & $v_{s t}$ \\
\hline Minimum & 1.54 & 4.55 & 2140.20 & 77.94 & 27.41 & 697.31 & 0.17 \\
\hline Maximum & 25.48 & 10.68 & 3075.56 & 162.49 & 119.57 & 854.01 & 0.43 \\
\hline Mean & 15.39 & 7.83 & 2634.51 & 138.62 & 76.39 & 803.07 & 0.25 \\
\hline Mode & 1.54 & 4.55 & 2140.20 & 77.94 & 27.41 & 697.31 & 0.17 \\
\hline Median & 16.27 & 8.25 & 2685.02 & 139.15 & 79.90 & 809.77 & 0.20 \\
\hline Standard deviation & 6.44 & 1.65 & 205.33 & 11.08 & 19.15 & 48.38 & 0.08 \\
\hline Skewness & -0.37 & -0.37 & -0.78 & -1.98 & -0.55 & -1.19 & 0.50 \\
\hline Kurtosis & 2.15 & 1.91 & 2.53 & 10.81 & 2.41 & 3.17 & 1.39 \\
\hline
\end{tabular}

The developed RF model presented high matching accuracy with $R$ values of 0.99 and 0.94 and AAPE values of $1.89 \%$ and $5.19 \%$ for processes of training and testing. The significant fitting was indicated by the cross plots and graphical representations of predicted and actual $v_{s t}$, as presented in Figures 5 and 6. 


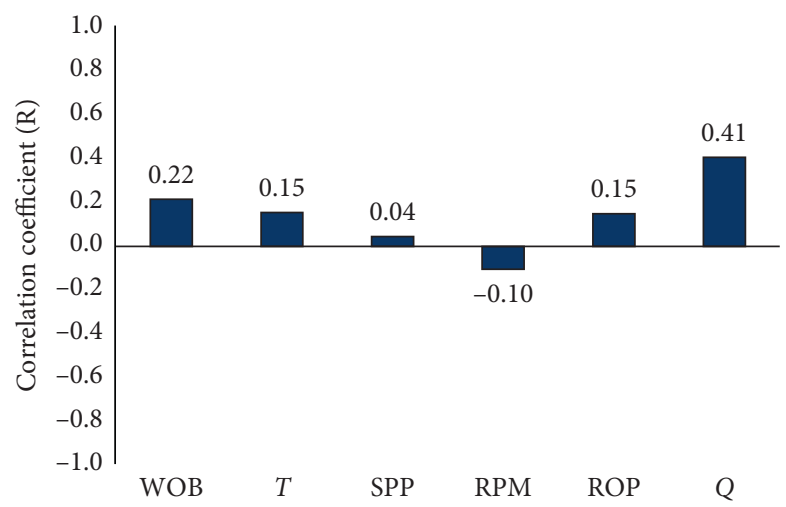

FIGURE 1: The correlation coefficient between static Poisson's ratio and drilling parameters.

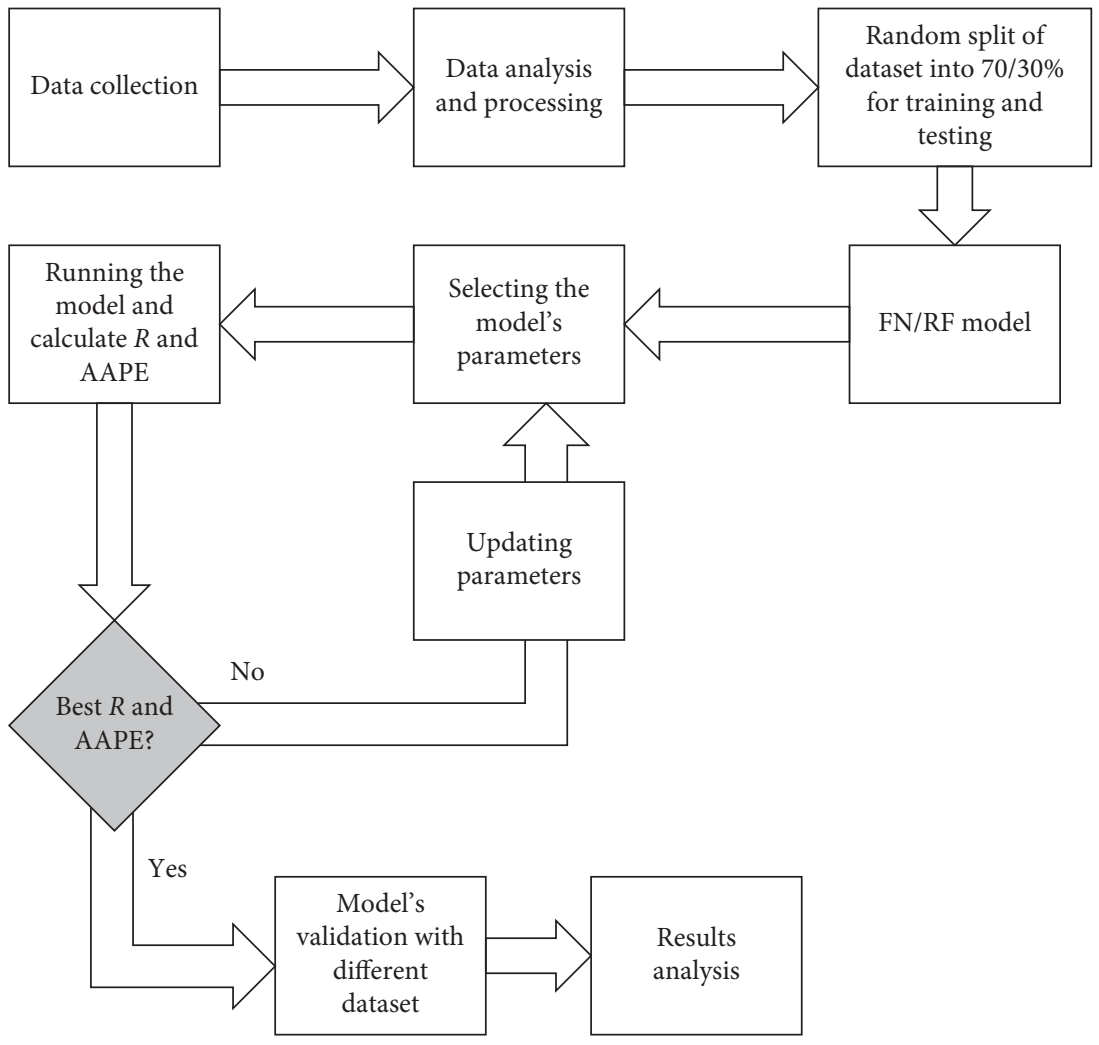

Figure 2: Flowchart of the FN/RF model development.

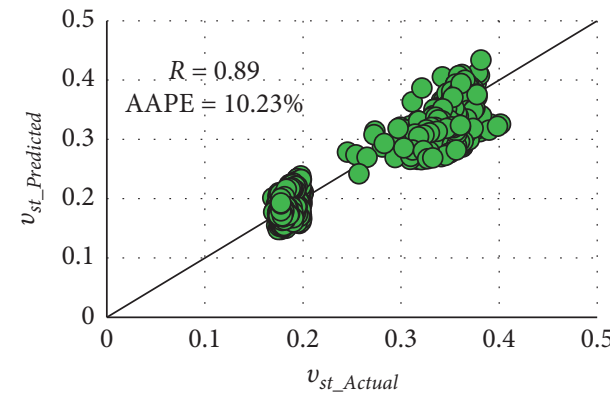

(a)

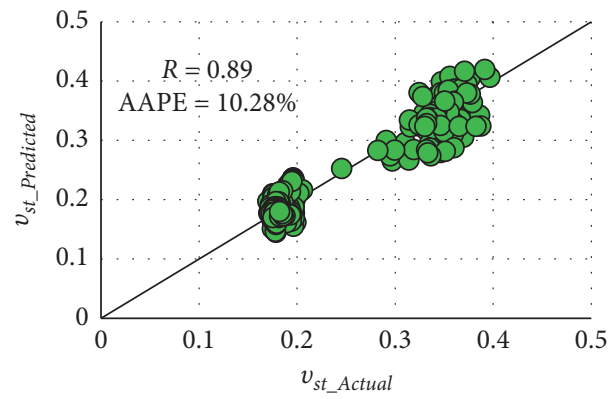

(b)

Figure 3: Cross plots of actual and FN-based predicted static Poisson's ratio in (a) training and (b) testing. 


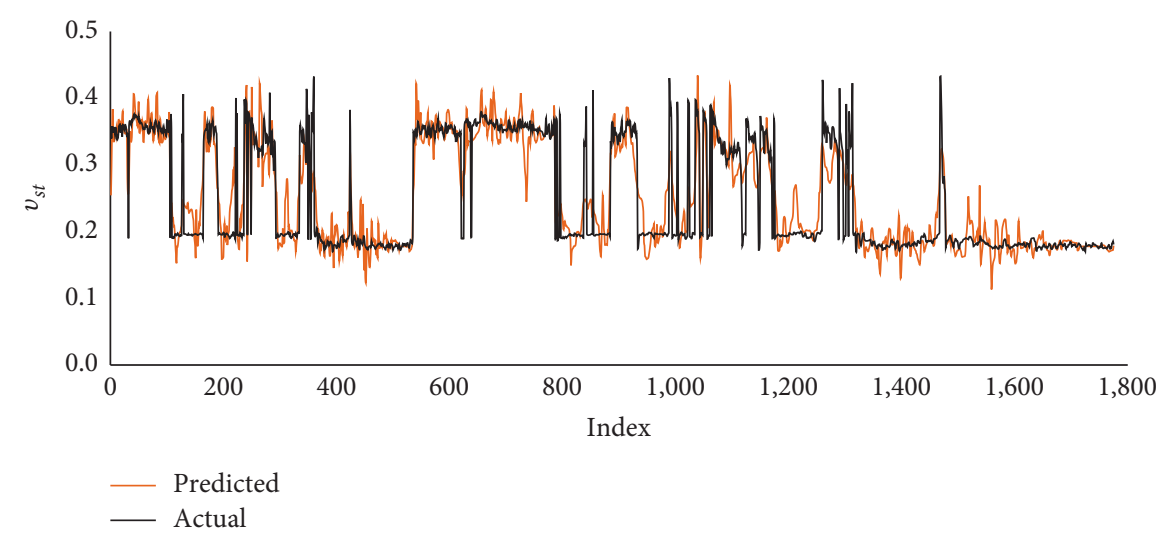

Figure 4: Graphical representations of actual and FN-based predicted static Poisson's ratio.

TABLE 4: Optimum set of parameters for the RF model.

\begin{tabular}{lc}
\hline Parameter & Value \\
\hline n_estimators & 100 \\
max_depth & 17 \\
max_features & Sqrt \\
min_samples_split & 2 \\
min_samples_leaf & 1 \\
\hline
\end{tabular}

3.3. Models'Validation. The reliability of the built models was evaluated using the second well's dataset. This set included 762 records with drilling parameters and corresponding $v_{s t}$.

The obtained results with the validation dataset indicated good matching accuracy with $R$ values of 0.86 and 0.94 and AAPE values of $11.23 \%$ and $5.12 \%$ for FN- and RF-based models, respectively. These results assured the robustness of the developed models and the superiority of the RF model. The cross plots and graphical representations of the predicted and actual $v_{s t}$ are depicted in Figures 7 and 8.

\section{Discussion}

This paper treated the interest of using the AI approaches for $v_{s t}$ prediction, to reduce the costs of experiments and overcome the missed data issue for providing a continued profile of $v_{s t}$. A real field data was used for this scientific and professional research.

An iterative approach was applied to find the optimal parameters of each model. From that, the highest fitting in the RF model was acquired with 100 decision trees, depth of each tree as 15, square root option for maximum number of features, min_samples_split as 2, and one minimum sample leaf size, while the backward-forward method with the nonlinear type was the optimum parameters for the $\mathrm{FN}$ approach.

The optimality of the two models was evaluated according to the $R$, AAPE, cross plots, and graphical representations. As a result, both models predicted the real-time $v_{s t}$ with outperformance in the RF-based model.

As it is impractical to predict a continued profile of $v_{s t}$ from experiments because of the high expenses, the constructed models are able to estimate $v_{s t}$ in real time with the least errors. However, the shortness of the developed models was represented by the inputs and outputs' range, as only the intermediate hole section was investigated in these models, so wider lithologies should be examined. Also, the application of the hybrid model to improve the selection of models' parameters instead of iterative methods is recommended for further works as well as the use of other AI techniques.

Comparing the two models indicated that the RF approach had an outperformance in predicting the real-time $v_{s t}$ with better $R$ and AAPE values, as presented in Figure 9. The fitting indices for the two models were outlined in Table 5. 


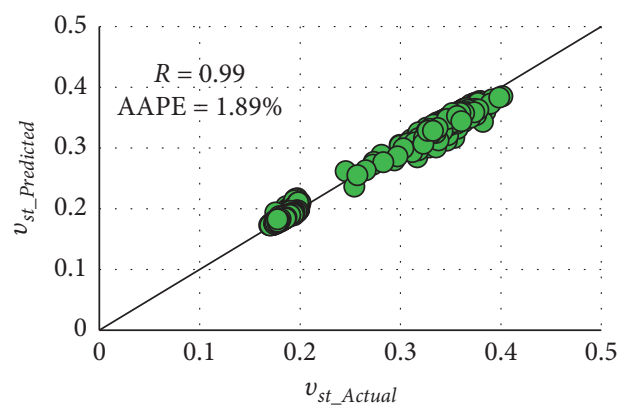

(a)

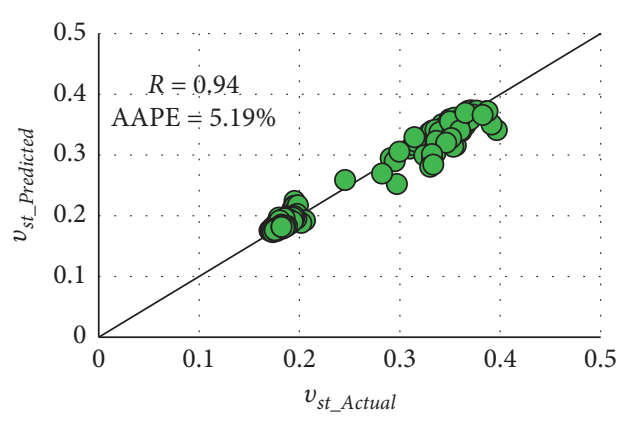

(b)

Figure 5: Cross plots of actual and RF-predicted static Poisson's ratio in (a) training and (b) testing.

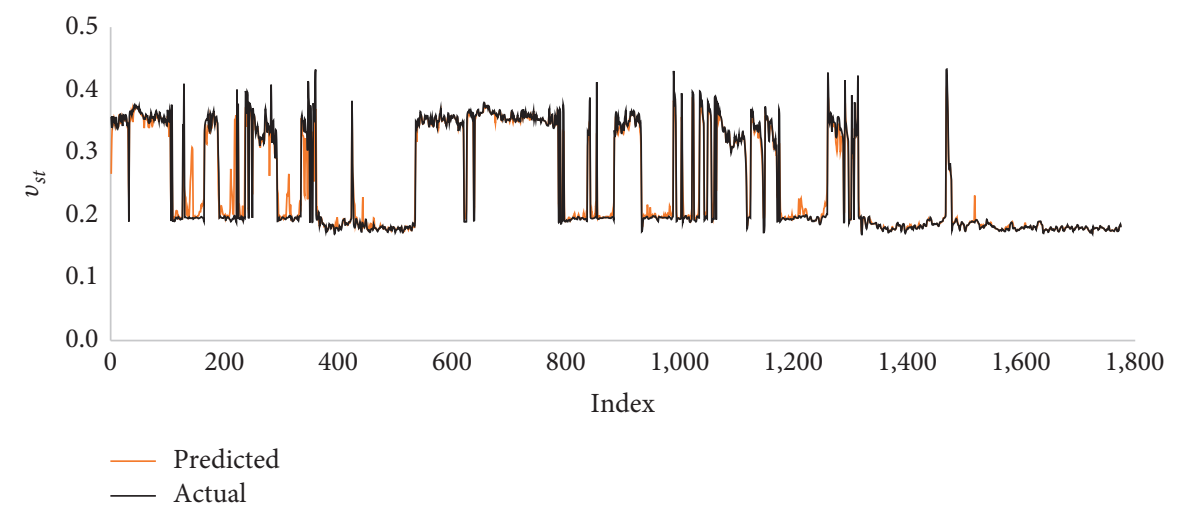

Figure 6: Graphical representations of actual and RF-based predicted static Poisson's ratio.

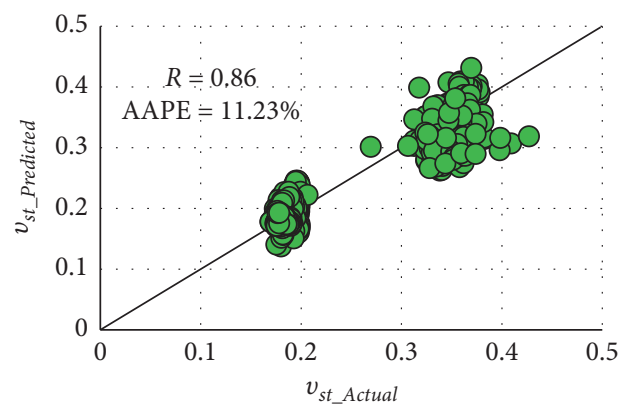

(a)

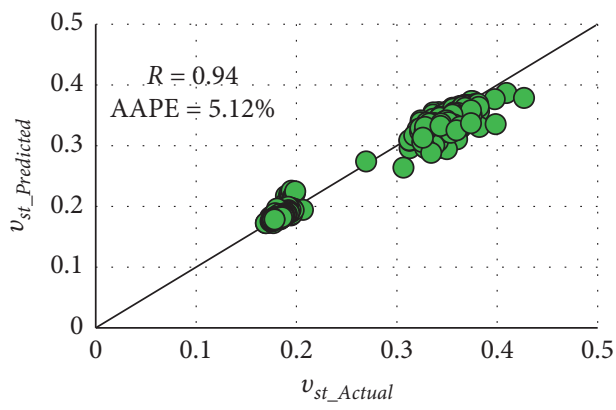

(b)

FIgURe 7: Cross plots of actual and predicted static Poisson's ratio of the validation dataset in (a) FN and (b) RF. 


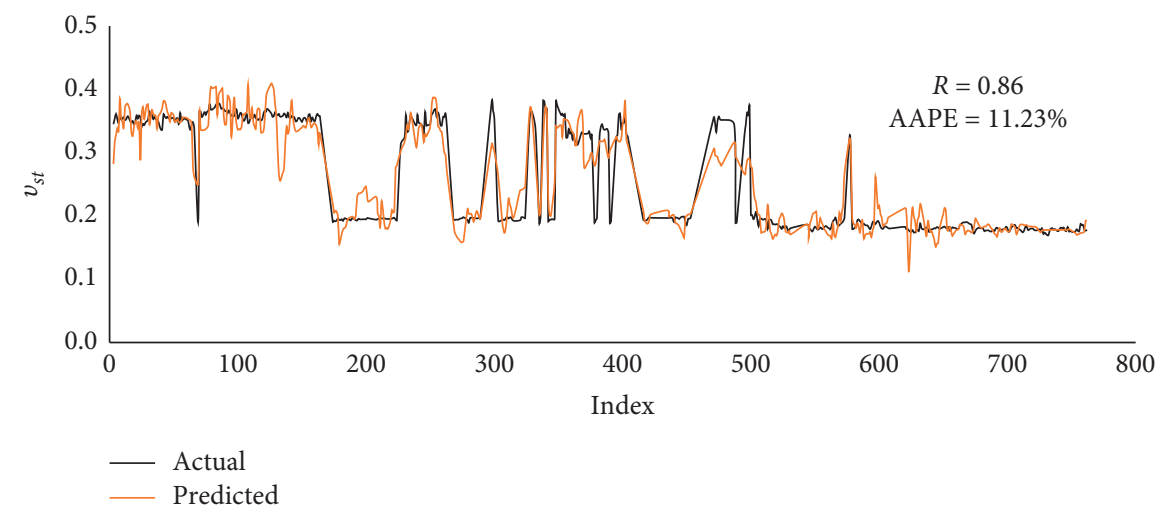

(a)

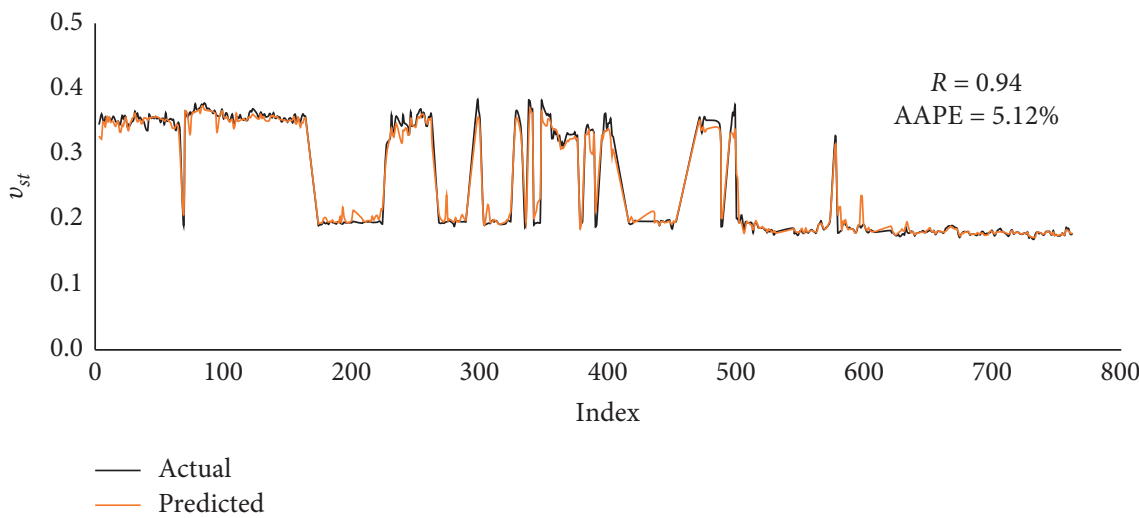

(b)

FIGURE 8: Graphical representations of actual and predicted static Poisson's ratio of the validation dataset in (a) FN and (b) RF.

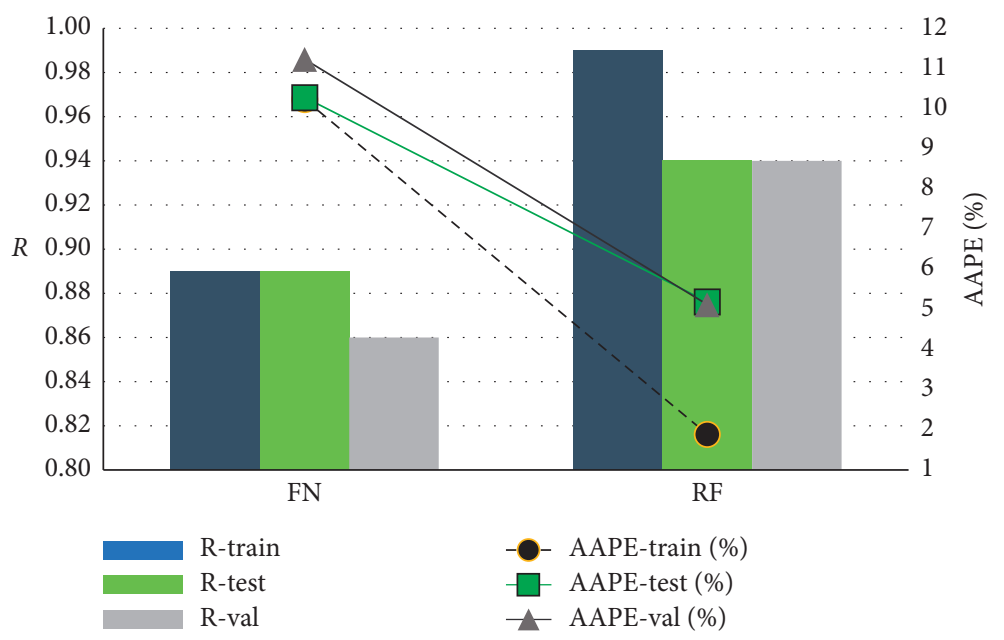

FIgUre 9: Comparison between FN- and RF-based models.

TABLE 5: The fitting indices for the constructed models.

\begin{tabular}{lcccccc}
\hline & & $R$ & & \multicolumn{2}{c}{ AAPE, \% } \\
& Training & Testing & Validation & Training & Testing & Validation \\
\hline FN & 0.89 & 0.89 & 0.86 & 10.23 & 10.28 & 11.23 \\
RF & 0.99 & 0.94 & 0.94 & 1.89 & 5.19 & 5.12 \\
\hline
\end{tabular}




\section{Conclusions}

Two AI models using FN and RF techniques were provided for real-time prediction of static Poisson's ratio from the drilling parameters (WOB, RPM, SPP, T, ROP, and Q). A vertical well containing complex lithology with carbonate, shale, and sand was used to build the models utilizing the real field measurements. The main deliverables of this work are summarized as follows:

(i) The FN model resulted acceptable fitting with the $R$ value of 0.89 and AAPE values of $10.23 \%$ and $10.28 \%$ in training and testing processes

(ii) The RF-based model outperformed in both training and testing processes with $R$ values of 0.99 and 0.94 and AAPE values of $1.89 \%$ and $5.19 \%$

(iii) The models were validated with a different dataset from another well confirming the models' applicability as it resulted in good prediction fitting with $R$ values of 0.86 and 0.94 and AAPE values of $11.23 \%$ and $5.12 \%$ for $\mathrm{FN}$ and RF models, respectively

(iv) Since the experimental measurements of static Poisson's ratio is highly expensive and not always available, the constructed models developed a basis for predicting a continuous profile at real time in inexpensive methods with the least errors

\section{Abbreviations}

AAPE:

Average absolute percentage error
ACE:

AI:

ANFIS:

ANN:

BE:

BF:

DE:

ES:

FB:

FL:

FN:

FS:

max_depth:

max_features:

min_sample_leaf:

min_samples_split: Minimum number of samples required

n_estimators:

ROP:

RPM:

SPP:

SVM:

$\mathrm{T}$ :

WOB:

\section{Appendix}

The $R$ and AAPE values used to evaluate the optimality of each model are calculated using the following equations:
Alternating conditional expectation Artificial intelligence

Adaptive neuro-fuzzy inference system Artificial neural network

Backward elimination

Backward-forward

Differential evolution algorithm

Exhaustive search

Forward backward

Fuzzy logic

Functional networks

Forward selection

Depth of decision tree

Maximum number of features

Minimum sample leaf size required to be at the end node

to split an internal node

Number of decision trees

Rate of penetration, $\mathrm{ft} / \mathrm{hr}$

Rotation speed, rotation per minute

Support vector machines

Torque, $\mathrm{klb}_{\mathrm{f}} \mathrm{ft}$

Weight on bit, $\mathrm{klb}_{\mathrm{m}}$
Standpipe pressure, psi

$$
\begin{aligned}
R & =\frac{\left[N \sum\left(v_{\text {st_Actual }} \times \rho_{\text {b_Predicted }}\right)\right]-\left[\sum v_{\text {st_Actual }} \times \sum v_{\text {st_Predicted }}\right]}{\sqrt{\left[N \sum\left(v_{\text {st_Actual }}\right)^{2}-\left(\sum v_{\text {st_Actual }}\right)^{2}\right]\left[N \sum\left(v_{\text {st_Predicted }}\right)^{2}-\left(\sum v_{\text {st_Predicted }}\right)^{2}\right]}}, \\
\text { AAPE } & =\frac{\sum\left|v_{\text {st_Actual }}-v_{\text {st_Pre di cte d }} / v_{\text {st_Actual }}\right| \times 100}{N},
\end{aligned}
$$

where $v_{\text {st_Actual }}$ and $v_{\text {st_Predicted }}$ are the measured and the model-based predicted static Poisson's ratio, respectively and $N$ represents the number of datapoints.

\section{Symbols}

$a, b, c$, and $d$ : Different empirical constants

$N$ : $\quad$ Number of datapoints

Q: $\quad$ Pumping rate, gal/minute

$R: \quad$ Correlation coefficient

$V_{P}: \quad$ Compressional-wave velocity, $\mathrm{km} / \mathrm{s}$

$V_{S}: \quad$ Shear-wave velocity, $\mathrm{km} / \mathrm{s}$

$V_{S h}: \quad$ Shale volume factor $v_{d y n}: \quad$ Dynamic Poisson's ratio

$v_{s t}$ : Static Poisson's ratio.

\section{Data Availability}

All data used to support the findings of the study are available within the article and can be obtained from the corresponding author upon request.

\section{Conflicts of Interest}

The authors declare that there are no conflicts of interest regarding the publication of this paper. 


\section{Acknowledgments}

The authors would like to thank King Fahd University of Petroleum \& Minerals (KFUPM) for employing its resources in performing this work.

\section{References}

[1] E. Fjar, R. M. Holt, A. M. Raaen, and P. Horsrud, Petroleum Related Rock Mechanics, vol. 53, Elsevier Science, Amrsterdam, The Netherland, 2008, 9780080557090.

[2] V. Labudovic, "The effect of Poisson's ratio on fracture height," Journal of Petroleum Technology, vol. 36, no. 02, pp. 287-290, 1984.

[3] J. Kumar, "The effect of Poisson's ratio on rock properties," in Proceedings of the SPE Annual Fall Technical Conference and Exhibition, Society of Petroleum Engineers, New Orleans, LA, USA, October 1976.

[4] O.-M. Nes, E. Fjær, J. Tronvoll, T. G. Kristiansen, and P. Horsrud, "Drilling time reduction through an integrated rock mechanics analysis," in Proceedings of the SPE/IADC Drilling Conference, Society of Petroleum Engineers, Amsterdam, Netherlands, February2005.

[5] R. Hammah, J. Curran, and T. Yacoub, "The influence of young's modulus on stress modelling results," in Proceedings of the Golden Rocks 2006, The 41st U.S. Symposium on Rock Mechanics (USRMS), American Rock Mechanics Association, Golden, CO, USA, June 2006.

[6] B. Christaras, F. Auger, and E. Mosse, "Determination of the moduli of elasticity of rocks. Comparison of the ultrasonic velocity and mechanical resonance frequency methods with direct static methods," Materials and Structures, vol. 27, no. 4, pp. 222-228, 1994.

[7] C. Feng, Z. Wang, X. Deng et al., "A new empirical method based on piecewise linear model to predict static Poisson's ratio via well logs," Journal of Petroleum Science and Engineering, vol. 175, pp. 1-8, 2019.

[8] Q. Wang, S. Ji, S. Sun, and D. Marcotte, "Correlations between compressional and shear wave velocities and corresponding Poisson's ratios for some common rocks and sulfide ores," Tectonophysics, vol. 469, no. 1-4, pp. 61-72, 2009.

[9] O. E. Agwu, J. U. Akpabio, S. B. Alabi, and A. Dosunmu, "Artificial intelligence techniques and their applications in drilling fluid engineering: a review," Journal of Petroleum Science and Engineering, vol. 167, pp. 300-315, 2018.

[10] A. S. Popa and S. D. Cassidy, "Artificial intelligence for heavy oil assets: the evolution of solutions and organization capability," in Proceedings of the SPE Annual Technical Conference and Exhibition, Society of Petroleum Engineers, San Antonio, TX, USA, October 2012.

[11] O. Bello, J. Holzmann, T. Yaqoob, and C. Teodoriu, “Application of artificial intelligence methods in drilling system design and operations: a review of the state of the art," Journal of Artificial Intelligence and Soft Computing Research, vol. 5, no. 2, pp. 121-139, 2015.

[12] Y. Guo, R. O. Hansen, and N. Harthill, "Feature recognition from potential fields using neural networks," in Proceedings of the SEG Technical Program Expanded Abstracts 1992, pp. 1-5, Society of Exploration Geophysicists, Houston, TX, USA, 1992.

[13] A. Kononov, D. Gisolf, and E. Verschuur, "Application of neural networks to traveltime computation," in Proceedings of the SEG Technical Program Expanded Abstracts 2007, pp. 1785-1789, Society of Exploration Geophysicists, Houston, TX, USA, 2007.

[14] A. Gowida, S. Elkatatny, and S. Elkatatny, "Prediction of sonic wave transit times from drilling parameters while horizontal drilling in carbonate rocks using neural networks," Petrophysics - The SPWLA Journal of Formation Evaluation and Reservoir Description, vol. 61, no. 5, pp. 482-494, 2020.

[15] C. Ross, "Improving resolution and clarity with neural networks," in Proceedings of the SEG Technical Program Expanded Abstracts 2017, pp. 3072-3076, Society of Exploration Geophysicists, Houston, TX, USA, 2017.

[16] A. Al-abduljabbar, S. Elkatatny, A. Abdulhamid Mahmoud et al., "Prediction of the rate of penetration while drilling horizontal carbonate reservoirs using the self-adaptive artificial neural networks technique," Sustainability, vol. 12, no. 4, p. 1376, 2020.

[17] A. Gowida, S. Elkatatny, K. Abdelgawad, and R. Gajbhiye, "Newly developed correlations to predict the rheological parameters of high-bentonite drilling fluid using neural networks," Sensors, vol. 20, no. 10, p. 2787, 2020.

[18] I. N. Tansel, C. Mekdeci, O. Rodriguez, and B. Uragun, "Monitoring drill conditions with wavelet based encoding and neural networks," International Journal of Machine Tools and Manufacture, vol. 33, no. 4, pp. 559-575, 1993.

[19] E. Govekar and I. Grabec, "Self-organizing neural network application to drill wear classification," Journal of Engineering for Industry, vol. 116, no. 2, pp. 233-238, 1994.

[20] R. Haber-Haber, R. Haber, M. Schmittdiel, and R. M. del Toro, "A classic solution for the control of a high-performance drilling process," International Journal of Machine Tools and Manufacture, vol. 47, no. 15, pp. 2290-2297, 2007.

[21] S. Akin and C. Karpuz, "Estimating drilling parameters for diamond bit drilling operations using artificial neural networks," International Journal of Geomechanics, vol. 8, no. 1, pp. 68-73, 2008.

[22] A. Gajate and R. Haber, "Internal model control based on a neurofuzzy system for network applications. a case study on the high-performance drilling process," IEEE Transactions on Automation Science and Engineering, vol. 6, no. 2, pp. 367372, 2009.

[23] A. Gajate, R. E. Haber, P. I. Vega, and J. R. Alique, "A transductive neuro-fuzzy controller: application to a drilling process," IEEE Transactions on Neural Networks, vol. 21, no. 7, pp. 1158-1167, 2010.

[24] Y. Wang and S. Salehi, "Drilling hydraulics optimization using neural networks," in Proceedings of the SPE Digital Energy Conference and Exhibition, Society of Petroleum Engineers, the Woodlands, TX, USA, March 2015.

[25] A. Yang, M. Wu, J. Hu, L. Chen, C. Lu, and W. Cao, "Discrimination and correction of abnormal data for condition monitoring of drilling process," Neurocomputing, vol. 433, pp. 275-286, 2021.

[26] A. Ali, T. Aifa, and K. Baddari, "Prediction of natural fracture porosity from well log data by means of fuzzy ranking and an arti fi cial neural network in Hassi Messaoud oil fi eld , Algeria," Journal of Petroleum Science and Engineering, vol. 115, pp. 78-89, 2014.

[27] M. A. Ahmadi, M. Pournik, and S. R. Shadizadeh, "Toward connectionist model for predicting bubble point pressure of crude oils: application of artificial intelligence," Petroleum, vol. 1, no. 4, pp. 307-317, 2015.

[28] M. A. Ahmadi, R. Soleimani, M. Lee, T. Kashiwao, and A. Bahadori, "Determination of oil well production performance using artificial neural network (ANN) linked to the 
particle swarm optimization (PSO) tool," Petroleum, vol. 1, no. 2, pp. 118-132, 2015.

[29] B. Shokooh Saljooghi and A. Hezarkhani, "A new approach to improve permeability prediction of petroleum reservoirs using neural network adaptive wavelet (wavenet)," Journal of Petroleum Science and Engineering, vol. 133, pp. 851-861, 2015.

[30] M. A. Oloso, M. G. Hassan, M. B. Bader-El-Den, and J. M. Buick, "Hybrid functional networks for oil reservoir PVT characterisation," Expert Systems with Applications, vol. 87, pp. 363-369, 2017.

[31] D. A. Wood and A. Choubineh, "Transparent open-box learning network and artificial neural network predictions of bubble-point pressure compared," Petroleum, vol. 6, no. 4, pp. 375-384, 2020.

[32] M. R. Mahdiani and M. Norouzi, "A new heuristic model for estimating the oil formation volume factor," Petroleum, vol. 4, no. 3, pp. 300-308, 2018.

[33] A. Al-abduljabbar, K. Al-azani, K. Al-Azani, and S. Elkatatny, "Estimation of reservoir porosity from drilling parameters using artificial neural networks," Petrophysics - The SPWLA Journal of Formation Evaluation and Reservoir Description, vol. 61, no. 3, pp. 318-330, 2020.

[34] A. Gowida, S. Elkatatny, S. Al-afnan, and A. Abdulraheem, "New computational artificial intelligence models for generating synthetic formation bulk density logs while drilling," Sustainability, vol. 12, no. 2, p. 686, 2020.

[35] H. A. Khalifah, P. W. J. Glover, and P. Lorinczi, "Permeability prediction and diagenesis in tight carbonates using machine learning techniques," Marine and Petroleum Geology, vol. 112, Article ID 104096, 2020.

[36] D. A. Wood, "Predicting porosity, permeability and water saturation applying an optimized nearest-neighbour, machine-learning and data-mining network of well-log data," Journal of Petroleum Science and Engineering, vol. 184, Article ID 106587, 2020.

[37] R. Zhong, R. Johnson, and Z. Chen, "Generating pseudo density log from drilling and logging-while-drilling data using extreme gradient boosting (XGBoost)," International Journal of Coal Geology, vol. 220, Article ID 103416, 2020.

[38] A. Ahmed, S. Elkatatny, H. Gamal, and A. Abdulraheem, "Artificial intelligence models for real-time bulk density prediction of vertical complex lithology using the drilling parameters," Arabian Journal for Science and Engineering, 2021.

[39] A. Abdulraheem, M. Ahmed, A. Vantala, and T. Parvez, "Prediction of rock mechanical parameters for hydrocarbon reservoirs using different artificial intelligence techniques," SPE, Article ID 126094, 2009.

[40] B. D. Al-anazi, M. T. Algarni, M. Tale, and I. Almushiqeh, "Prediction of Poisson's ratio and young's modulus for hydrocarbon reservoirs using alternating conditional expectation algorithm," in Proceedings of the SPE Middle East Oil and Gas Show and Conference, Society of Petroleum Engineers, Manama, Bahrain, September 2011.

[41] Z. Tariq, S. M. Elkatatny, M. A. Mahmoud, A. Abdulraheem, A. Z. Abdelwahab, and M. Woldeamanuel, "Estimation of rock mechanical parameters using artificial intelligence tools," in Proceedings of the 51st U.S. Rock Mechanics/Geomechanics Symposium, American Rock Mechanics Associatio, San Francisco, CA, USA, June 2017.

[42] S. M. Elkatatny, Z. Tariq, M. A. Mahmoud, Z. A. Abdulraheem Abdelwahab, M. Woldeamanuel, and I. M. Mohamed, "An artificial intelligent approach to predict static Poisson's ratio," in Proceedings of the 51st U.S. Rock Mechanics/Geomechanics Symposium, American Rock Mechanics Association, San Francisco, CA, USA, June 2017.

[43] S. Elkatatny, "Application of artificial intelligence techniques to estimate the static Poisson's ratio based on wireline log data," Journal of Energy Resources Technology, vol. 140, no. 7, pp. 1-8, 2018.

[44] Z. Tariq, A. Abdulraheem, A. Abdulraheem, M. Mahmoud, and A. Ahmed, "Borehole resistivity measurement modeling using machine-learning techniques," Petrophysics - The SPWLA Journal of Formation Evaluation and Reservoir Description, vol. 59, no. 6, pp. 761-777, 2018.

[45] A. Abdulraheem, "Prediction of Poisson's ratio for carbonate rocks using ANN and fuzzy logic type-2 approaches," in Proceedings of the International Petroleum Technology Conference, International Petroleum Technology Conference, Beijing, China, March 2019.

[46] A. Gowida, T. Moussa, S. Elkatatny, and A. Ali, "A hybrid artificial intelligence model to predict the elastic behavior of sandstone rocks," Sustainability, vol. 11, no. 19, p. 5283, 2019.

[47] A. Ahmed, S. Elkatatny, and A. Abdulraheem, "Real-time static Poisson's ratio prediction of vertical complex lithology from drilling parameters using artificial intelligence models," Arabian Journal of Geosciences, vol. 14, no. 6, p. 436, 2021.

[48] A. T. J. Bourgoyne, K. K. Millheim, M. E. Chenevert, and F. S. Young, Applied Drilling Engineering, vol. 2, Society of Petroleum Engineers, Houston, TX, USA, 1986, 9781555630010.

[49] G. Mensa-Wilmot, B. Calhoun, and V. P. Perrin, "Formation drillability-definition, quantification and contributions to bit performance evaluation," in Proceedings of the SPE/IADC Middle East Drilling Technology Conference, Society of Petroleum Engineers, Abu Dhabi, UAE, November 1999.

[50] J. W. González, R. Valdez, J. Torres, and F. Medina, "Identification of zones of abnormal pressures and determination of the mechanical properties of the rock through pseudo-sonic and pseudo-density logs in conventional and unconventional reservoirs," in Proceedings of the SPE Argentina Exploration and Production of Unconventional Resources Symposium, Society of Petroleum Engineers, Neuquén, Argentina, August 2018.

[51] S. R. Masini, S. Goswami, A. Kumar, and B. Chennakrishnan, "Decline curve analysis using artificial intelligence," in Proceedings of the Abu Dhabi International Petroleum Exhibition \& Conference, Society of Petroleum Engineers, Abu Dhabi, UAE, November 2019. 